\title{
EL PAPEL DE LAS REPARACIONES EN LA JUSTICIA TRANSICIONAL COLOMBIANA: APORTES DESDE UNA VISIÓN TELEOLÓGICA*
}

\author{
THE ROLE OF REPARATIONS IN THE \\ COLOMBIAN TRANSITIONAL JUSTICE: \\ CONTRIBUTIONS FROM A \\ TELEOLOGICAL PERSPECTIVE
}

\author{
Maria Carmelina Londoño-Lázaro** \\ María Del Pilar Gutiérrez-Perilla**** \\ Paula Andrea Roa-SÁncheZ**** \\ Fecha de recepción: 30 de abril de 2017 \\ Fecha de aceptación: 15 de mayo de 2017 \\ Disponibilidad en línea: 30 de junio de 2017
}

\section{Para Citar Este Artículo / To Cite This Article}

Londoño-Lázaro, María Carmelina, Gutiérrez-Perilla, María del Pilar \& Roa-Sánchez, Paula Andrea, El papel de las reparaciones en la justicia transicional colombiana: aportes desde una visión teleológica, 30 International Law, Revista Colombiana de Derecho Internacional, 119-150 (2017). https:// doi.org/10.11144/ Javeriana.il 15-30.prjt

doi:10.11144/Javeriana.i115-30.prjt

* El presente estudio es fruto de las reflexiones suscitadas en el ámbito del Grupo de investigación en Derecho Internacional de la Universidad de La Sabana y, especialmente, del enriquecedor debate que tuvo lugar con numerosos profesores en el foro "Acuerdos de Paz y Derecho Internacional", organizado por la Maestría en Derecho Internacional de la misma Institución, en marzo de 2017.

** Doctora en Derecho, LLM, Abogada. Directora de la Maestría en Derecho Internacional e investigadora de la Escuela de Ciencias Económicas y Administrativas (EICEA) de la Universidad de La Sabana; miembro fundadora de la Academia Colombiana de Derecho Internacional (actual vicepresidente) y de la Sociedad Latinoamericana de Derecho Internacional. Contacto: maria.londono1@unisabana.edu.co

*** Magíster en Derecho Internacional, Maestría Internacional en Derechos Humanos y Democratización, Especialización (M. A.) en Estudios, Políticos Económicos y Culturales Avanzados, Abogada. Docente Universitaria, miembro del Grupo de investigación en Derecho Internacional de la Universidad de La Sabana, Asesora en litigio del grupo de Defensa Internacional de la Agencia Nacional de Defensa Jurídica del Estado. Contacto: mapigu86@gmail.com

**** Investigadora auxiliar del Grupo de Investigación en Derecho Internacional de la Universidad de La Sabana, practicante en investigación en la Facultad de Derecho y Ciencias de la misma universidad, becaria del programa Jóvenes Talentos de Cundinamarca de la Fundación Ceiba. Contacto: paularoasa@unisabana.edu.co 
El reconocimiento e implementación de medidas de reparación constituye un aspecto cardinal en las sociedades en transición como la colombiana. El presente artículo se pregunta por el fundamento del deber de reparar a las víctimas de violaciones a los derechos humanos a partir de diversas teorías de justicia y propone una visión teleológica como la más adecuada para lograr las aspiraciones últimas de una sociedad que busca superar el conflicto y lograr una paz estable y duradera. Este enfoque propone potenciar el papel de las reparaciones de cara a los fines últimos de la justicia transicional, articulando derechos individuales y colectivos, así como condiciones favorables para avanzar en los proyectos de vida personales de las víctimas y de la sociedad en general, a partir de la reivindicación de la noción de bien común. Así pues, se plantea una lógica pluridimensional que rescata tres dimensiones de las reparaciones: individual, colectiva y trascendental. Partiendo de lo anterior, se formulan algunos efectos jurídico-políticos prácticos que resultarían de la aplicación de esta visión teleológica pluridimensional.

Palabras clave: justicia transicional; reparaciones; teorías de la justicia; bien común 


\section{ABSTRACT}

The recognition and implementation of reparation measures is a cardinal aspect in societies undergoing a transitional process such as Colombia. This article seeks to analyze the basis of the obligation of granting reparations to victims of human rights violations from diverse theories of justice. For this, it proposes a teleological vision as the most adequate to achieve the ultimate aspirations of a society that seeks to overcome an armed conflict and to achieve a sustainable and lasting peace. This approach emphasizes on the role of reparations as part of the main goals of transitional justice, articulating individual and collective rights, as well as adequate conditions for advancing victims' and societies' life projects, through the vindication of the notion of common good. Thus, the article presents a multidimensional logic that involves the three dimensions of reparations: individual, collective and transcendental. Following this concept, it formulates some practical legal-political effects which would result from the application of this multidimensional teleological vision.

Keywords: Transitional justice; reparations; justice theories; common good

SUMARIO

INTRODUCCIÓN. I. REPARACIONES Y PRINCIPIOS DE JUSTICIA: LAS REPARACIONESCOMO EXIGENCIAS DE LA JUSTICIA. II. LOS PRINCIPIOS DE JUSTICIA QUE SUBYACEN A LA OBLIGACIÓN DEL ESTADO DE REPARAR A LAS VÍCTIMAS DEL CONFLICTO ARMADO. III. REPARACIONES Y BIEN COMÚN EN SOCIEDADES EN TRANSICIÓN. IV. VOCACIÓN TRANSFORMADORA Y ORIENTACIÓN TELEOLÓGICA DE LAS REPARACIONES. V. A MODO DE COLOFÓN: CONSECUENCIAS PRÁCTICAS DE UNA PERSPECTIVA TELEOLÓGICA. BIBLIOGRAFÍA 
INTRODUCCIÓN

\section{El debate público sobre la reparación integral a víctimas del con- flicto armado ${ }^{1}$ y las preocupaciones que han generado estudios especializados sobre el programa colombiano de reparaciones en el marco de la justicia transicional, ${ }^{2}$ nos han incentivado a pensar en la justificación de que la carga social de las repara- ciones sea asumida por todos los colombianos y en el papel que estas juegan de cara a los fines últimos que persigue un modelo de justicia transicional, en particular, la consolidación de la paz y la reconciliación social. ${ }^{3}$}

1 Solo para mencionar algunos de esos debates en torno a la reparación a víctimas del conflicto armado colombiano en la esfera pública, pueden referenciarse, entre otros, los siguientes: Congreso de la República. Gacetas del Congreso. Senado de la República: 776/2015; 21/2016; 6/10/2015; 14/2016; 890/2015; 1042/2015; 113/2016; 158/2016; 405/2016; 364/2016; Cámara de Representantes: 943/2015; 1010/2015; 29/11/2015; 09/10/2015; 890/2015; 1043/201; 276/2016; 367/2016. (2015-2016).

2 Centro Carr para la Política de Derechos Humanos y la Iniciativa Humanitaria de Harvard. Evaluación de medidas de reparación integral: logros y retos. https://www.yumpu.com/es/ document/view/55955747/evaluacion-de-medidas-para-reparaciones-integrales-en-colombialogros-y-retos (octubre de 2015).

3 En el derecho internacional, la justicia transicional ha sido entendida como una respuesta que se genera en los Estados durante periodos de conflicto o violencia generalizada, caracterizados por violaciones sistemáticas a los derechos humanos, cuyos objetivos centrales son reconocer a las víctimas y promover iniciativas de paz, reconciliación y democracia. Así entendida, en el ámbito de la ONU, como se señalará en este estudio, la justicia transicional es una justicia adaptada a sociedades que se transforman a sí mismas después de un periodo de violación generalizada de los derechos humanos.

En concordancia con esta visión internacional, la Corte Constitucional colombiana ha explicado la justicia transicional como "una institución jurídica a través de la cual se pretende integrar diversos esfuerzos, que aplican las sociedades para enfrentar las consecuencias de violaciones masivas y abusos generalizados o sistemáticos en materia de derechos humanos, sufridos en un conflicto, hacia una etapa constructiva de paz, respeto, reconciliación y consolidación de la democracia, situaciones de excepción frente a lo que resultaría de la aplicación de las instituciones penales corrientes". Corte Constitucional de Colombia, Sala Plena, Sentencia C-052 de 2012, Expediente D-8593, Actor: Jesús Antonio Espitia Marín, Magistrado Ponente: Nilson Pinilla Pinilla. En síntesis, por la complejidad del conflicto colombiano, el modelo de justicia transicional se ha construido con distintas piezas, fundamentalmente normas y decisiones judiciales, tal como lo ha afirmado la Dirección de Justicia Transicional del Ministerio de Justicia y del Derecho. Dentro de las normas fundamentales se cuentan las siguientes: Ley 975 de 2005 "de Justicia y Paz", por la cual se dictan disposiciones para la reincorporación de miembros de grupos armados organizados al margen de la ley, que contribuyan de manera efectiva a la consecución de la paz nacional y se dictan otras disposiciones para acuerdos humanitarios, 45980 Diario Oficial, 25 de julio de 2005. La Ley1448 de 2011 "de Víctimas y Restitución de tierras", por la cual se dictan medidas de atención, asistencia y reparación integral a las víctimas del conflicto armado interno y se dictan otras disposiciones, 48096 Diario Oficial, 10 de junio de 2011. El Acto legislativo 01 de 2012 "marco jurídico para la paz", por medio del cual se establecen instrumentos jurídicos de justicia transicional en el marco del artículo 22 de la Constitución Política y se dictan otras disposiciones, 48508 Diario Oficial, 31 de julio de 2012. 
¿Por qué es justo que todos asumamos los costos de los daños ocasionados por los grupos ilegales y agentes del Estado que violaron derechos humanos? Esta es la pregunta que muchos colombianos se hacen y que genera tanta polarización y controversia. Tanto el derecho internacional como el nacional defienden la figura de las reparaciones como un derecho fundamental de las víctimas, ${ }^{4}$ por lo que esta cuestión, en última instancia, atañe a un problema de justicia. Sin embargo, las distintas teorías de la justicia pueden justificar de modos muy diversos la necesidad y alcance de las reparaciones en una sociedad en transición. Luego de un análisis sintético de las principales limitaciones que ofrecen algunas teorías de la justicia de cara a las aspiraciones últimas de la justicia transicional, resulta iluminadora para nuestros propósitos, la postura que el filósofo político Michael Sandel fundamenta inspirado en Aristóteles. ${ }^{5}$ A partir de esta posición y de los aportes de otros autores ha sido posible redescubrir la trascendencia que tiene el concepto de bien común para fundamentar el valor de las reparaciones en una sociedad en transición.

A partir de aquel marco teórico adaptado al contexto de nuestro objeto de estudio, así como la riqueza que ofrecen algunos instrumentos internacionales, en este trabajo se propone también una visión teleológica del papel que juegan las reparaciones en

El Acto legislativo 01 de 2017, por medio del cual se crea un título de disposiciones transitorias de la constitución para la terminación del conflicto armado y la construcción de una paz estable y duradera y se dictan otras disposiciones, 50196 Diario Oficial, 4 de abril de 2017. Por su parte, entre la jurisprudencia constitucional más relevante para fijar las bases y lineamientos del actual modelo -que en estricto sentido sigue en construcción- pueden referenciarse las decisiones comúnmente denominadas "Marco jurídico para la paz I" y "Marco jurídico para la paz II": Corte Constitucional de Colombia, Sala Plena, Sentencia C-579 de 2013, Expediente D-9499, Magistrado sustanciador: José Ignacio Pretelt Chaljub. Corte Constitucional de Colombia, Sala Plena, Sentencia C-577 de 2014, Expediente D-9819, Magistrada Ponente: Martha Victoria Sáchica Méndez.

4 Organización de Naciones Unidas, Principios y directrices básicos sobre el derecho de las víctimas de violaciones manifiestas de las normas internacionales de derechos humanos y de violaciones graves del derecho internacional humanitario a interponer recursos y obtener reparaciones, Asamblea General 147/ 2005,16 de diciembre de 2005; la citada Ley 1448 de 2011, por la cual se dictan medidas de atención, asistencia y reparación integral a las víctimas del conflicto armado interno y se dictan otras disposiciones, 48096 Diario Oficial, 10 de junio de 2011; y, entre otra jurisprudencia constitucional, puede verse: Corte Constitucional de Colombia, Sala Plena, Sentencia SU-254 de 2013, Expediente T-2.406.014 y acumulados, Magistrado Ponente: Luis Ernesto Vargas Silva.

5 Michael J. Sandel, Justicia: ¿Hacemos lo que debemos? (Ed. Random House Mondadori, Barcelona, 2011). 
la transición. En esta propuesta se plantea que, para potenciar el papel de las reparaciones en función de los fines últimos de un modelo de justicia transicional, resulta indispensable reivindicar la noción de bien común como pieza clave que permite la articulación entre derechos individuales y colectivos, así como entre proyectos de vida personales y fines comunes. Esta perspectiva implica, entonces, entender el componente de reparaciones de un sistema integral de justicia transicional con las siguientes claves: 1) es necesario superar los principios de justicia meramente correctiva o conmutativa que tradicionalmente han inspirado el derecho individual a obtener reparación integral; 2) las reparaciones para víctimas de graves violaciones a derechos humanos deben estar orientadas al establecimiento de las condiciones necesarias para que se puedan restablecer los proyectos de vida personales y comunitarios, lo que implica incluir la lógica de la justicia distributiva en el diseño de los programas de reparación y 3) los fines comunes a los que se aspira con la transición son la guía de orientación tanto del diseño como de la implementación de los programas de reparaciones.

Esta lógica puede llamarse pluridimensional ${ }^{6}$ en cuanto rescata al menos tres distintas dimensiones de las reparaciones: individual, colectiva y trascendental. En el presente trabajo se definen los alcances de cada dimensión y se plantea cómo esta articulación, que en definitiva conjuga los elementos del bien común, resulta coherente con la aspiración de reconstrucción del tejido social, condición para una paz estable y duradera.

Con esta perspectiva del papel que pueden jugar las reparaciones en función de los fines últimos que justifican un modelo de justicia transicional, se plantean algunas consecuencias prácticas, a modo de efectos jurídico-políticos que se desprenderán de la concepción teleológica y pluridimensional: 1) si bien el concepto de bien común sirve para justificar la garantía de los programas de reparaciones a cargo del Estado, ese mismo concepto constituye un límite para determinar el alcance de

6 Algunos podrían denominarla holística. 
los compromisos de reparación; 2) el debate público sobre los programas de reparaciones tendrá que asumir nuevos conceptos (no principalmente enfocados en cuantías económicas) que giran en torno a los principios y valores que se privilegian en el posconflicto, como condiciones para consolidar la paz; 3) resulta urgente presentar evidencias públicas de los avances en la implementación de los programas de reparaciones pluridimensionales, como respaldo a un compromiso serio del Estado en la materia; 4) si el compromiso al que se refiere el punto anterior es probado, el alcance del principio de subsidiariedad impondrá a los órganos internacionales de derechos humanos un especial self-restraint, para dictaminar reparaciones por fuera del sistema nacional.

Para cumplir con los objetivos trazados, el escrito se divide en cinco secciones. En la primera se revisa el concepto de reparaciones y su relación con la justicia; en la segunda se ponen en evidencia los principios de justicia que subyacen a la obligación del Estado de reparar a las víctimas del conflicto armado de acuerdo con diversas teorías de la justicia y se analizan las ventajas de una concepción teleológica para justificar la "carga social" que implica tal obligación; la tercera sección formula un planteamiento de relación entre reparaciones y bien común, desde el que se explica la relevancia de la visión pluridimensional y teleológica que se expone en este estudio; en desarrollo de lo anterior, la cuarta sección resalta la posibilidad e importancia de que las reparaciones promuevan las condiciones necesarias para la reconfiguración de los proyectos de vida personales, la transformación de deficiencias estructurales y el logro de fines comunes de la sociedad. Al final del estudio se presentan como conclusiones algunas consecuencias prácticas del análisis y la propuesta que se ha expuesto. 


\section{REPARACIONES Y PRINCIPIOS DE JUSTICIA: LAS REPARACIONES COMO EXIGENCIAS DE LA JUSTICIA}

Las reparaciones a víctimas de graves violaciones a los derechos
humanos y al derecho internacional humanitario ${ }^{7}$ resultan ser, en
primer lugar, una exigencia de justicia conmutativa, en la medida en la que se reconoce la deuda de un agresor con la víctima y se le provee a esta la titularidad para reclamar y hacer efectiva tal deuda, definida en virtud de la naturaleza y magnitud de los daños infligidos. Se trata pues de corregir o remediar los daños derivados de un hecho ilícito. En el derecho internacional se ha reconocido ampliamente este derecho de carácter individual o colectivo y su correlación con la justicia ${ }^{8}$ así como sus distintas manifestaciones, esto es, la restitución plena del derecho conculcado y, cuando sea procedente, las indemnizaciones por los perjuicios materiales y morales consumados, las medidas de rehabilitación física, psíquica o psicosocial de las víctimas, modalidades de satisfacción y garantías de no repetición. ${ }^{9}$

7 Por sustracción de materia, tanto las violaciones a derechos contenidos en el derecho internacional de los derechos humanos, como a derechos contenidos en el derecho internacional humanitario, son violaciones a derechos humanos, con lo cual a lo largo del texto se hará la referencia genérica a 'violaciones a derechos humanos'.

8 Así, expresamente los Principios y directrices básicos sobre el derecho de las víctimas de violaciones manifiestas de las normas internacionales de derechos humanos y de violaciones graves del derecho internacional humanitario a interponer recursos y obtener reparaciones, establecen en el num. 15 que: "Una reparación adecuada, efectiva y rápida tiene por finalidad promover la justicia, remediando las violaciones manifiestas de las normas internacionales de derechos humanos o las violaciones graves del derecho internacional humanitario. La reparación ha de ser proporcional a la gravedad de las violaciones y al daño sufrido [...]”. Organización de Naciones Unidas. Asamblea General. Principios y directrices básicos sobre el derecho de las victimas de violaciones manifiestas de las normas internacionales de derechos humanos y de violaciones graves del derecho internacional humanitario a interponer recursos y obtener reparaciones. Resolución 147/2005 (16 de diciembre de 2005).

9 Principios y directrices básicos sobre el derecho de las víctimas de violaciones manifiestas de las normas internacionales de derechos humanos y de violaciones graves del derecho internacional humanitario a interponer recursos y obtener reparaciones, nums. 15-23. Sobre las garantías de no repetición como una modalidad de reparación, aunque no nos resulta convincente esta idea, se incorpora tal cual ha sido esgrimida para seguir fielmente los desarrollos que han hecho tanto Naciones Unidas como el Sistema Interamericano de Derechos Humanos. Se ha hecho un estudio previo en el que se critica esta asociación, fundamentalmente sobre la base de la muy distinta naturaleza y titularidad que corresponde a las reparaciones -que miran al pasado para remediar los daños ocurridos a las víctimas-y las garantías de no repetición-que tienen vocación de futuro y amplitud de beneficiarios-. Véase, María Carmelina Londoño. 


\section{La jurisprudencia de la Corte Interamericana de Derechos} Humanos (Corte IDH) ha consolidado esta visión de las reparaciones como un derecho, al decir que:

La reparación del daño ocasionado por la infracción de una obligación internacional requiere, siempre que sea posible, la plena restitución (restitutio in integrum), la cual consiste en el restablecimiento de la situación anterior a la violación. De no ser esto posible, como en el presente caso, cabe al tribunal internacional determinar una serie de medidas para que, además de garantizar el respeto de los derechos conculcados, se reparen las consecuencias producidas por las infracciones y se establezca, inter alia, el pago de una indemnización como compensación por los daños ocasionados. [...] Las reparaciones consisten en las medidas que tienden a hacer desaparecer los efectos de las violaciones cometidas. Su naturaleza y su monto dependen del daño ocasionado en los planos material e inmaterial. Las reparaciones no pueden implicar ni enriquecimiento ni empobrecimiento para la víctima o sus sucesores. ${ }^{10}$

Siguiendo esos lineamientos del derecho internacional, en Colombia se ha adoptado una visión de la reparación como un derecho fundamental de las víctimas del conflicto armado, cuya garantía se encuentra a cargo del Estado, independientemente de los autores de los ilícitos particulares. Prueba de ello es la Ley 1448 que estipula que "[1]as víctimas tienen derecho a ser reparadas de manera adecuada, diferenciada, transformadora y efectiva por el daño que han sufrido como consecuencia de las violaciones de que trata el artículo $3^{\circ}$ de la presente ley". ${ }^{11}$ En la misma línea, la jurisprudencia constitucional ha reconocido que:

El derecho a la reparación de las víctimas es integral, en la medida en que se deben adoptar distintas medidas determinadas no solo por la justicia distributiva sino también por la justicia restaurativa, en cuanto

Las garantías de no repetición en la jurisprudencia interamericana. Derecho Internacional y cambios estructurales del Estado. (Ed. Tirant lo Blanch, 2014).

10 Corte IDH, Caso Masacre de Pueblo Bello. Sentencia de 31 de enero de 2006. Serie C. N. ${ }^{\circ}$ 140, párrs. 228-229; Corte IDH, Caso Masacres de Ituango contra Colombia. Sentencia de 1 de julio de 2006. Serie C N. ${ }^{\circ}$ 148, párrs. 347-348; Corte IDH, Caso Acosta y otros contra Nicaragua. Excepciones preliminares, fondo, reparaciones y costas. Sentencia de 25 de marzo de 2017. Serie C N. ${ }^{\circ} 334$, párr. 210.

11 Colombia, Ley 1448 de 2011, por la cual se dictan medidas de atención, asistencia y reparación integral a las víctimas del conflicto armado interno y se dictan otras disposiciones, 48096 Diario Oficial, 10 de junio de 2011, artículo 25. 
se trata de la dignificación y restauración plena del goce efectivo de los derechos fundamentales de las víctimas ${ }^{12}$.

Así también, el Acuerdo firmado entre el Gobierno colombiano y las FARC-EP entiende el concepto de reparaciones:

Las víctimas tienen derecho a ser resarcidas por los daños que sufrieron a causa del conflicto. Restablecer los derechos de las víctimas y transformar sus condiciones de vida en el marco del fin del conflicto es parte fundamental de la construcción de la paz estable y duradera. ${ }^{13}$

Si bien es cierto que el derecho a la reparación integral de víctimas de graves violaciones a los derechos humanos ha sido ampliamente reconocido en el derecho internacional y sobre esos lineamientos se ha construido la figura en el ámbito nacional colombiano, el concepto y exigencias de las reparaciones no resulta ser tan pacífico cuando se le inserta en un escenario de justicia transicional, debido a que el número de víctimas, las exigencias de una reparación integral y los costos correlativos hacen inviable mantener la lógica de las reparaciones otorgadas por tribunales internacionales en los casos concretos. Un desafío, entonces, del marco excepcional de transición es adaptar los estándares, mecanismos y procesos ordinarios al propósito general de resolver los graves abusos del pasado con el fin de alcanzar los objetivos principales orientados a que "los responsables rindan cuentas de sus actos, servir a la justicia y lograr la reconciliación". ${ }^{14}$

Tanto el marco transicional colombiano como los expertos de Naciones Unidas coinciden en ratificar la importancia de las reparaciones como uno de los pilares de cualquier sistema de

12 Corte Constitucional de Colombia, Sala Plena, Sentencia SU-254 de 2013, Expedientes T-2.406.014 y acumulados. Magistrado Ponente: Luis Ernesto Vargas Silva, párrs. 4.2.3.

13 Acuerdo final para la terminación del conflicto y la construcción de una paz estable y duradera. $\mathrm{http} / /$ www.altocomisionadoparalapaz.gov.co/procesos-y-conversaciones/Documentos\%20 compartidos/24-11-2016NuevoAcuerdoFinal.pdf (Acuerdo de paz). (26 de noviembre de 2016). Punto 5.

14 Organización de Naciones Unidas, Informe del Relator Especial sobre la promoción de la verdad, la justicia, la reparación y las garantías de no repetición Pablo de Greiff, Asamblea General, A/HRC/21/46, 9 de agosto de 2012. 
justicia transicional. El primer informe oficial del Consejo de Seguridad de las Naciones Unidas sobre El Estado de derecho y la justicia de transición en las sociedades que sufren o han sufrido conflictos, señala que está demostrado que:

No es posible consolidar la paz en el periodo inmediatamente posterior al conflicto ni mantenerla a largo plazo a menos que la población confíe en que se podrá obtener la reparación de las injusticias sufridas a través de estructuras legítimas encargadas del arreglo pacífico de las controversias y la correcta administración de justicia. ${ }^{15}$

De un modo semejante, la ley de víctimas, ${ }^{16}$ la jurisprudencia constituciona $1{ }^{17}$ y el Acuerdo Final entre el Gobierno colombiano y las FARC-EP ${ }^{18}$ conceden un lugar privilegiado a las reparaciones a las víctimas del conflicto armado y las reconocen como uno de los pilares esenciales de la transición hacia la paz.

Se observa entonces que respecto del reconocimiento del derecho a la reparación de las víctimas de graves violaciones a derechos humanos, como una exigencia de la justicia, existe un amplio consenso; sin embargo, los desafíos y dificultades se presentan en el modo como se interpreta ese principio general y se concreta en contextos altamente complejos como el caso

15 Organización de las Naciones Unidas, Primer informe oficial del Consejo de Seguridad de las Naciones Unidas sobre El Estado de derecho y la justicia de transición en las sociedades que sufren o han sufrido conflicto, Consejo de Seguridad S/2004/616, 3 de agosto de 2004, 4.

16 Colombia, Ley 1448 de 2011, supra nota 3.

17 Corte Constitucional de Colombia, Sala Plena, Sentencia C-006 de 2017, Expediente D-11481, Magistrado Sustanciador: Gloria Stella Ortiz Delgado; Corte Constitucional de Colombia, Sala Plena Sentencia SU-254 de 2013, Expedientes T-2.406.014 y acumulados. Magistrado Ponente: Luis Ernesto Vargas Silva; reiterada en Corte Constitucional de Colombia, Sala Plena, Sentencia C-912 de 2013, Expediente D-9683, actores: Luis Jorge Garay Salamanca y otros. Magistrada Ponente María Victoria Calle Correa; Corte Constitucional de Colombia, Sala Plena, Sentencia C-286 de 2014, Expediente D-9930, Actor: Gustavo Gallón Giraldo y otros. Magistrado Ponente: Luis Ernesto Vargas Silva; Corte Constitucional de Colombia, Sala Plena, Sentencia C-370 de 2006, Expediente D-6032, Actor: Gustavo Gallón Giraldo y otros, Magistrados Ponentes: Manuel José Cepeda Espinosa, Jaime Córdoba Triviño, Rodrigo Escobar Gil, Marco Gerardo Monroy Cabra, Álvaro Tafur Galvis, Clara Inés Vargas Hernández; Corte Constitucional de Colombia, Sala Plena, Sentencia C-916 de 2002, Expediente: D-4020, Actor: Camilo Andrés Baracaldo Cárdenas. Magistrado Ponente: Manuel José Cepeda Espinosa; Corte Constitucional de Colombia, Sala Plena, Sentencia C-333 de 1996, Expediente D-1111, Actora: Emilse Margarita Palencia Cruz. Magistrado Ponente: Alejandro Martínez Caballero.

18 Supra nota 13. 
colombiano. ${ }^{19}$ Por eso, la pregunta por los fines últimos de la justicia transicional es una cuestión definitiva para seguir enriqueciendo el debate público sobre la justificación de la carga social que imponen las reparaciones masivas y el papel que ellas juegan en una sociedad en transición como la de Colombia. Una posición mayoritaria, con la que coincidimos, reconoce que las reparaciones resultan ser una pieza clave en la consecución de los fines a los que aspira un modelo de justicia transicional,,$^{20} \mathrm{en}$ particular, la reconstrucción del tejido social para alcanzar el valor fundamental de la paz, entendida en términos generales, como un modo de convivencia social armónica, así como la consolidación del Estado de derecho. ${ }^{21}$

Sin duda, aunque es posible llegar a la misma conclusión por diversas vías, la teoría de la justicia desde la cual se evalúa el papel que cumplen las reparaciones en una sociedad en transición, afectará necesariamente el modo como se les justifique y su alcance. Uno de los objetivos de este trabajo es poner en evidencia esos distintos marcos teóricos, señalando de manera muy sintética las posibilidades que ofrecen y sus limitaciones para

19 Tanto las reparaciones individuales como las colectivas presentan dificultades a la hora de su concreción. Así, por ejemplo, el informe del Consejo de Seguridad de las Naciones Unidas señala algunas problemáticas asociadas a las indemnizaciones y que dan luces de las muchas exigencias prácticas que acarrean: "Es difícil decidir a quién incluir entre las víctimas que recibirán una indemnización, a cuánto ascenderá dicha indemnización, qué tipo de perjuicios indemnizar, cómo evaluarlos, cómo comparar y compensar los diferentes tipos de perjuicios y cómo distribuir las indemnizaciones". Consejo de Seguridad de las Naciones Unidas. Primer informe oficial del Consejo de Seguridad de las Naciones Unidas sobre El Estado de derecho y la justicia de transición en las sociedades que sufren o han sufrido conflicto. Véase supra nota 15. Evidentemente, en el contexto colombiano, estas consideraciones pueden extenderse también a las medidas de rehabilitación y satisfacción a víctimas del conflicto.

20 El Relator Especial sobre la promoción de la verdad, la justicia, la reparación y las garantías de no repetición, Pablo de Greiff, ha adoptado una visión global e interrelacionada de esos cuatro componentes básicos de la justicia transicional, entre los que se cuentan expresamente las reparaciones. Tal perspectiva de interrelación entre esos diversos componentes permite avanzar con una visión integral de la justicia de transición, en la que se reconoce el peso de las reparaciones y, al mismo tiempo, se ponderan sus exigencias en el marco de una política integrada. Véase supra nota 14.

21 Estos fines coinciden con la propuesta del Relator De Greiff, al afirmar que los elementos fundamentales de un modelo de transición "verdad, justicia, reparación y no repetición" están vinculados entre sí de manera interrelacionada para "contribuir a la consecución de dos objetivos mediatos: el reconocimiento de las víctimas y el fomento de la confianza, y dos objetivos finales: la reconciliación y la consolidación del Estado de derecho". Supra nota 14, párr. 64. 
justificar el papel del Estado como garante de las reparaciones, cuestión que se desarrolla en el siguiente acápite.

\section{LOS PRINCIPIOS DE JUSTICIA QUE SUBYACEN A LA OBLIGACIÓN DEL ESTADO DE REPARAR A LAS VÍCTIMAS DEL CONFLICTO ARMADO}

El derecho de las víctimas a obtener reparaciones y la consecuente obligación del Estado de garantizarlas en un escenario de posconflicto con diversidad de actores, podría justificarse de muy diversos modos, no necesariamente excluyentes entre ellos, pero sí preferibles unos sobre otros, en virtud de los principios sobre los que se asientan esas justificaciones y su alineación con los fines que se persiguen en una transición. En esta sección se han elegido algunas de esas posibles justificaciones y se propone un análisis que alerta sobre la selección de valores que se hace en cada opción, todo con el fin de demostrar que una perspectiva teleológica de la justicia resulta ser la más coherente para justificar la responsabilidad del Estado -y, en consecuencia, de todos los contribuyentes- de garantizar las reparaciones y potenciar el papel que cumplen en un modelo de justicia transicional. El marco teórico de estas diversas opciones se encuentra inspirado en el análisis sistemático de las teorías de la justicia que ofrece Michael Sandel. ${ }^{22}$

Desde una concepción liberal individualista, el daño producido a las víctimas debe ser reparado en virtud de una exigencia básica de justicia correctiva y, quizá también desde este ángulo, podría justificarse la primacía de fórmulas de justicia retributiva. La razón fundamental por la que el Estado está obligado a garantizar el derecho a la reparación de las víctimas es porque su intervención es necesaria para corregir el desequilibrio que se produce por la grave afectación a la libertad individual de las víctimas, expresada en términos de derechos humanos. En su versión más extrema, un libertario como Nozik que aboga por

22 Supra nota 5. Para profundizar sobre tales teorías, remitimos al lector directamente a esta obra. 
un "Estado mínimo", justificará la tarea del Estado de garantizar las reparaciones en un modelo de justicia transicional, solo y en tanto se protege a las víctimas por el mal causado por los agresores y se les resarcen los daños sufridos.

Como puede observarse, si se es coherente con esta postura, no corresponden consideraciones de justicia distributiva ni restaurativa para alentar la tarea del Estado en materia de reparaciones, pues no le cabe a este apelar a otros principios distintos a corregir y castigar, so pena de coartar la libertad individual al imponer valores comunes sin que necesariamente cada individuo se sienta identificado con ellos. ${ }^{23}$ Resulta entonces evidente que esta visión minimalista del Estado, con la correlativa magnificación de la libertad personal, trae consigo dificultades insalvables para asegurar la reconstrucción del tejido social y la reconciliación entre los diversos actores, como presupuestos de la paz, entre otras razones, porque el Estado no estaría facultado para privilegiar ciertos valores que sustenten fines comunes. Así, por ejemplo, difícilmente se podrían justificar políticas fundadas en valores como el perdón para la reintegración, la solidaridad con las víctimas, la confianza para alcanzar la reconciliación, etc.

Por su parte, una teoría utilitarista de la justicia defenderá la obligación del Estado de garantizar reparaciones a las víctimas solo y hasta el punto en el que el cálculo de los beneficios supere el de los costos. Por supuesto, en este escenario tampoco resultan de recibo criterios de justicia distributiva ni equidad. Una de las mayores dificultades que ofrece esta perspectiva es, justamente, el principio de cálculo de costos y beneficios. Estimar el peso y la magnitud de los bienes en juego en una sociedad que lucha por transformarse a sí misma para alcanzar la paz, resulta imposible si se piensa en las muchas variables y valores inconmensurables. Además, sensatamente, aunque sea en su versión más simple y con esto se corra el riesgo de descalificar el todo por la parte, parece indeseable una justificación que termina reduciéndose

23 Así, por ejemplo, un típico argumento libertario reniega del uso de los impuestos para compensar a víctimas de la violencia o financiar planes de reintegración de grupos desmovilizados sobre la base del desacuerdo personal con esos fines. 
a consideraciones económicas para establecer el alcance del derecho a la reparación. Una propuesta como la que ha hecho la comunidad internacional en favor de la reparación integral de las víctimas de graves violaciones a los derechos humanos -que ha sido acogida en el marco colombiano-, resulta difícilmente sostenible desde una perspectiva utilitaria, pues los fines últimos de paz y reconciliación, definitivamente, suponen sacrificios considerables y elección de otros valores distintos al "bienestar del mayor número de individuos".

Finalmente, una visión teleológica de la justicia, que puede ser defendida por muchas corrientes -entre ellos los comunitaristas, en la que se inscribe Sandel-, tendría que justificar la obligación del Estado de garantizar las reparaciones a las víctimas en el posconflicto en la medida en que estas resulten esenciales para alcanzar los fines del modelo de transición y tales fines sean legítimos. Desde esta perspectiva, la tarea del Estado supone no tanto garantizar que se corrijan las injusticias individuales con base en criterios de justicia conmutativa sino, primordialmente, establecer las condiciones más generales para lograr fines ulteriores como la reconciliación social y la paz, por lo que criterios de justicia distributiva, equidad y solidaridad resultan plausibles a la hora de establecer el componente de las reparaciones que faciliten el tránsito a una sociedad recompuesta.

Un argumento de oposición a esta postura señalaría que las elecciones de valores siempre son arbitrarias y que, en esa medida, el Estado no tendría por qué elegir un "modelo de vida buena" para todos, sino que tendría que dejar discurrir las elecciones y proyectos de vida a juicio de cada cual, so pena de quebrantar el principio de neutralidad del Estado. Al sinfín de argumentos y contraargumentos que pueden ofrecerse en esta línea, la discusión podría zanjarse invocando la naturaleza misma de la justicia transicional, en la que se evoca, justamente, la escogencia de unos valores sobre otros (a saber, la paz estable, el Estado de derecho, la reconciliación, la confianza, la solidaridad, entre otros), pues la neutralidad axiológica no existe en 
este terreno, como en ningún otro en el que se toman decisiones jurídicas y políticas.

En consecuencia, la propuesta que ofrece esta teoría teleológica de la justicia, adaptada a un marco de justicia transicional, justificaría que el Estado con su programa de reparaciones y otras piezas del modelo integral, aliente y promueva unas ciertas virtudes en los ciudadanos, que más allá de las ideas o preferencias personales, resulten necesarias para alcanzar los fines últimos de la transición: lograr la paz y la reconciliación social. Valores -o virtudes en el lenguaje clásico- como el perdón, la compasión, la fraternidad, la confianza, no son utopías en este escenario sino condiciones axiológicas necesarias para los fines a los que se aspira. El desafío es que tales valores logren integrarse y reconfigurarse armónicamente -no solo en el diseño como teóricamente podría apreciarse en el modelo colombiano-, sino, sobre todo, en la implementación de las reparaciones, para acomodarse a las exigencias que trae consigo una amalgama de principios de justicia conmutativa, distributiva, retributiva, restaurativa, transformativa y legal.

Esta dimensión teórica implica aceptar el criterio del bien común, en el que se conjugan tanto la necesidad de la realización personal como los fines sociales compartidos, como se verá en la siguiente sección. Por ahora, nos interesa dejar sentada la idea de que una justicia de transición impregnada de perspectiva teleológica parece ser la que más se ajusta a las visiones holísticas e integrales que la experiencia de la comunidad internacional propugna. ${ }^{24}$

Ahora bien, entendemos, como sostienen algunos estudios, que la concreción de las reparaciones en escenarios de justicia transicional puede acarrear ciertas tensiones entre principios de justicia correctiva y justicia distributiva. ${ }^{25} \mathrm{Sin}$ embargo, la pers-

24 Organización de Naciones Unidas. Informe del Relator Especial sobre la promoción de la verdad, la justicia, la reparación y las garantías de no repetición Pablo de Greiff, Asamblea General A/HRC/30/42, 7 de septiembre de 2015; supra notas 14, 15.

25 Morten Bersgsmo et al., Justicia distributiva en sociedades en transición (Torkel Opsahl Academic EPublisher \& Peace Research Institute Oslo, Oslo, 2012). A nuestro juicio, esta tensión se debe, prima facie, a una aparente yuxtaposición en las tareas que corresponden al Estado, 
pectiva teleológica da la posibilidad de integrar y armonizar las exigencias de una y otra en función de fines comunes mayores, de modo tal que en un escenario de tránsito del conflicto hacia la paz, las reparaciones no solo cumplen el papel de compensar el daño sufrido por las víctimas, sino que, en su comprensión más amplia, son herramientas para crear condiciones que hagan viable la paz. En razón a que son un pilar del modelo de justicia transicional, es necesario entenderlas no solo como una exigencia de la justicia correctiva o conmutativa, sino que es posible potenciar su papel a partir de la reivindicación de la noción de bien común, como se propone adelante.

\section{REPARACIONES Y BIEN COMÚN EN SOCIEDADES EN TRANSICIÓN}

Tal como lo ha reconocido el derecho internacional, las reparaciones hacen parte de los componentes esenciales de una política integral de transición. El Relator Especial sobre la promoción de la verdad, la justicia, la reparación y las garantías de no repetición ha propuesto una visión según la cual la conjugación de esos cuatro componentes es una condición para garantizar la percepción de justicia que resulta fundamental para hacer viable la transición a Estados de derecho sólidos y en paz. ${ }^{26}$ Partimos de la validez de esta premisa y no es objeto de este estudio discernir sobre las exigencias concretas que debe contemplar el programa de reparaciones en una etapa de posconflicto colombiano, sino más bien, rescatar el valor que estas tienen para la configuración de condiciones alineadas con una justicia pensada en términos teleológicos, marco en el que resulta fundamental reivindicar la noción de bien común.

por un lado, en su deber de protección de los derechos humanos según el cual debe garantizar las reparaciones debidas por los daños individuales o colectivos infringidos cualquiera sea el agente trasgresor $\mathrm{y}$, por otro lado, la exigencia relativa a la configuración de las condiciones necesarias para la terminación del conflicto armado y la subsiguiente reconciliación social orientada a garantizar una paz estable y duradera.

26 Supra nota 4. 
En este sentido es muy apropiado entender las exigencias generales de la justicia, al decir de Finnis, como "las implicaciones concretas de la exigencia básica de la razonabilidad práctica, según la cual uno ha de favorecer y promover el bien común de sus propias comunidades". ${ }^{27}$ Desde esta perspectiva el bien común se entiende como un resultado de la coordinación y colaboración efectiva entre las personas, recursos e instituciones con el ánimo de "aumentar el bienestar (o al menos las oportunidades de realizarse plenamente) de todos los miembros de una comunidad". 28

En este trabajo se propone que la noción de bien común es una pieza clave para superar algunas de las limitaciones derivadas de las visiones individualistas, libertarias y utilitaristas de las reparaciones y justificar que este componente esté a cargo del Estado, incluso cuando se trata de remediar violaciones masivas cometidas por grupos ilegales. Si bien es cierto que este concepto no es exclusivo de una teoría de la justicia, sí resulta indispensable para comprender la propuesta que hace Sandel inspirado en Aristóteles -el marco de referencia que nos ha parecido más acertado para pensar la justicia transicional-, según se explicó en el acápite anterior.

La visión del bien común que se defiende aquí aboga por entenderlo como un centro de armonización de intereses particulares y colectivos, producto de la participación articulada de todos los actores sociales (individuos, familias, asociaciones intermedias, empresas, Estados, organizaciones intergubernamentales, comunidad internacional, entre otros) con miras a contribuir al más alto desarrollo personal y comunitario. Así visto, el fin compartido por los miembros de la comunidad (fin común) no excluye los bienes particulares de los individuos que la integran, como sucede con el concepto de interés general que usualmente se encuentra en tensión con respecto al de interés particular. Por el contrario, la noción de bien común exige el

27 John Finnis, Ley natural y derechos naturales, 194 (Oxford, Clarendon Press, 1992).

28 John Finnis, Ley natural y derechos naturales, 195. 
bien particular de todos los integrantes de la comunidad -en el sentido de realización personal- ${ }^{29}$ pero no es que se calcule sobre bases estadísticas o utilitarias. A decir verdad, el bien común no es el "mayor bien del mayor número", sino un bien que a la vez que abarca a todos los miembros de la sociedad, supera las meras realizaciones individuales y se sitúa como:

El conjunto de condiciones materiales y espirituales, de muy variado contenido (políticas, sociales, económicas, culturales y educativas, urbanísticas y ambientales, etc.), que favorecen el normal y pleno desarrollo de la persona humana y de los grupos que integran la sociedad política y que han de ser creadas por y para todos y cada uno de sus integrantes, bajo el lúcido y limitado gobierno de la autoridad pública. ${ }^{30}$

Nótese que así entendido el bien común es mucho más conveniente para los propósitos últimos de la justicia transicional que el concepto de interés general. La noción de interés general, por oposición a la de interés particular o individual, se refiere más al interés de la colectividad objetivamente considerada y, visto así, muchas veces se usa para limitar el alcance de los derechos individuales o incluso, excepcionalmente, estos podrían sacrificarse en función de proteger aquel. De hecho, podría decirse que este es el equívoco en el que incurre Kalmanovitz, cuando sugiere que en contextos de transición de graves conflictos debe darse prioridad a la justicia social sobre la justicia correctiva, dando

29 Esta visión coincide con la teoría finniseana del personal flourishment, como sustrato de la noción de bien común. Para este autor, el bien común es un conjunto de condiciones materiales y de otro tipo, dentro de las cuales se cuentan los derechos humanos, que tiendan a favorecer y fomentar ese desarrollo personal de cada individuo que compone la comunidad. Supra nota 27, 177-185.

30 Santiago Alfonso. En las fronteras entre el Derecho Constitucional y la Filosofía del Derecho, 91 (Ed., Marcial Pons, Buenos Aires, 2010). La propuesta de Maritain en este mismo sentido es todavía más específica. Para este autor, esta misma idea de conjunto está compuesta tanto por las condiciones sociales necesarias para el desarrollo de los fines de la comunidad, como por "todo lo que supone conciencia cívica, de las virtudes políticas y del sentido del derecho y de la libertad y de todo lo que hay de actividad, de prosperidad material y de tesoros espirituales, de sabiduría tradicional inconscientemente vivida, de rectitud moral, de justicia, de amistad, de felicidad, de virtud y de heroísmo, en la vida individual de los miembros de la comunidad, en cuanto que todo esto es comunicable y se distribuye y es participado, en cierta medida, por cada uno de los individuos, ayudándoles así a perfeccionar su vida y su libertad de persona". Antonio Argandona, El bien común, Documento de Investigación DI-937, IESE Business School, julio de 2011. 
a entender que los derechos individuales de las víctimas están llamados a ceder ante las demandas sociales de la colectividad. ${ }^{31}$ Ese concepto de interés general, por tanto, difiere del de bien común porque este último supone la conjunción de los intereses o bienes de todos y cada uno de los miembros de la sociedad, encaminados todos ellos hacia un fin que les es común.

En términos semejantes, la Corte Interamericana ha acogido el siguiente concepto de bien común:

Es posible entender el bien común, dentro del contexto de la Convención, como un concepto referente a las condiciones de la vida social que permiten a los integrantes de la sociedad alcanzar el mayor grado de desarrollo personal y la mayor vigencia de los valores democráticos. En tal sentido, puede considerarse como un imperativo del bien común la organización de la vida social en forma que se fortalezca el funcionamiento de las instituciones democráticas y se preserve y promueva la plena realización de los derechos de la persona humana. ${ }^{32}$

Así entendido, el bien común exige la materialización de las reparaciones en cuanto resulten necesarias para que las víctimas de las más graves violaciones a los derechos humanos puedan rediseñar sus proyectos de vida, de tal modo que les sea posible alcanzar un cierto modo de realización personal, que se propicia no solo de manera individual, sino también en las comunidades más pequeñas, empezando por la familia. Así, la noción de reparaciones entendida desde la perspectiva de un modelo de justicia transicional como el que se ha propuesto para Colombia, centrado fundamentalmente en alcanzar la reconstrucción del tejido social para garantizar una paz operativa, requiere comprender las dimensiones individual, comunitaria y trascendental de las reparaciones.

31 Rodrigo Uprimny, Reparaciones transformadoras: un mecanismo para aliviar tensiones entre justicia correctiva y justicia distributiva, en Democracia, Justicia y Sociedad. Diez años de investigación en Dejusticia, 745 (Mauricio García y María Ceballos Coord., Dejusticia, Bogotá, 2016).

32 CIDH. La Colegiación Obligatoria de Periodistas (Arts. 13 y 29 Convención Americana sobre Derechos Humanos). Opinión Consultiva OC-5/85 del 13 de noviembre de 1985. Serie A N ${ }^{\circ}$ 5, párr. 66. En el párrafo anterior la Corte había anotado: "Es válido sostener, en general, que el ejercicio de los derechos garantizados por la Convención debe armonizarse con el bien común". 
La dimensión individual reconoce la titularidad de las víctimas a obtener reparaciones en función del daño particular que cada una ha sufrido; la colectiva o comunitaria identifica la titularidad del derecho de reparación a las personas que, en virtud de pertenecer a un grupo o comunidad, han padecido violaciones de derechos humanos como grupo, esto es porque en razón de su identidad o membresía han soportado injusticias como las de sus semejantes; finalmente, la dimensión trascendental propone entender las reparaciones también como una pieza clave desde la que se reconoce el derecho de la sociedad a restablecerse, a pesar de las graves heridas del pasado, con la ambición de alcanzar la reconciliación y la paz de manera estable. La perspectiva que proponemos supone una integración de las tres dimensiones - algunos podrían denominarla como una perspectiva holística-, según la cual no son suficientes cada una por sí misma, sino que las tres, de manera integrada, requerirán una especie de adaptación de las exigencias de cada una por separado, en función del bien común al que se aspira en sociedades en transición.

Una ventaja práctica considerable de esta visión se debe a que la noción de bien común no es una fórmula estática ni uniforme, sino más bien, justamente, atiende a las necesidades, aspiraciones, contexto y actores propios de cada sociedad, de manera que facilita la coordinación entre los distintos niveles de participantes con el ánimo de alcanzar las mejores condiciones posibles para la realización personal de los distintos miembros y colectividades de la sociedad en transición. ${ }^{33}$ Ese bien común al

33 Esta idea de adaptación al contexto coincide con el argumento que sugiere que el derecho internacional concede un amplio margen de apreciación a los Estados a la hora de configurar sus modelos de justicia transicional. Así lo expone, por ejemplo, el Relator Especial Pablo de Greiff: "En vista de la creciente tendencia a recurrir a medidas de búsqueda de la verdad, iniciativas de la justicia, reparación y garantías de no repetición sin tener en cuenta las características del entorno al que se aplican, [se] destaca la importancia crucial de identificar y evaluar claramente las condiciones de cada país y de abordarlas de forma certera, contextualizada y con fines específicos". Supra nota 14, párr. 18. En el mismo sentido, el primer informe de las Naciones Unidas especializado en Justicia de Transición expone claramente que "ninguna reforma del Estado de derecho, reconstrucción de la justicia o iniciativa de justicia de transición puede culminar con éxito y ser duradera si viene impuesta desde el exterior. El papel de las Naciones Unidas y la comunidad internacional debe ser de solidaridad y no de sustitución". Como corolario, se afirma que el papel de la comunidad internacional en sociedades en transición "consiste en facilitar 
que se hace referencia, puede coincidir parcialmente con la noción fundamental de orden social justo, desde la cual el relator De Greiff perfila los objetivos más particulares que deben perseguir las medidas de justicia de transición, esto es, el reconocimiento de las víctimas como titulares de derechos, el restablecimiento de la confianza de los distintos actores sociales entre ellos y con el Estado, así como la reconciliación social. ${ }^{34}$

En definitiva, pensar las reparaciones desde la perspectiva del bien común supone: 1) concebirlas de tal forma que su concreción facilite a las víctimas reconfigurar sus proyectos de vida individuales y comunitarios y 2) comprenderlas como piezas clave de un sistema integral de justicia transicional, cuyos fines comunes al trascender los bienes particulares de los distintos actores sociales, se convierten en las guías de orientación tanto del diseño como de la implementación de las distintas modalidades de reparación.

En la próxima sección ahondaremos en estas dos exigencias que se desprenden de una concepción teleológica de las reparaciones, fundadas sobre la base del bien común.

\section{VOCACIÓN TRANSFORMADORA Y ORIENTACIÓN TELEOLÓGICA DE LAS REPARACIONES}

Anteriormente se ha afirmado que las reparaciones en un modelo de justicia transicional pueden potenciar su papel si se les comprende, no desde una visión estrecha conmutativa-restitutiva, sino desde la óptica del bien común que combina, además, principios de justicia distributiva y restaurativa definidos en virtud de esos fines innegociables que se persiguen con la transición, esto es, sobre todo, la reconciliación social y la paz.

los procesos mediante los cuales los distintos interesados discuten y perfilan los elementos del plan de su país para hacer frente a las injusticias del pasado y garantizar una justicia duradera para el futuro, de conformidad con los principios internacionales, las tradiciones jurídicas propias y las aspiraciones nacionales". Supra nota 15, párr. 17.

34 Supra nota 14, párr. 44 ss. 
Entender las reparaciones como exigencias del bien común supone, entonces, comprenderlas como derechos de las víctimas pero que no están fundamentalmente centrados en el resarcimiento proporcional del daño causado por el agresor, sino que su objeto más importante es la configuración de condiciones que permitan a las víctimas alcanzar su más plena realización personal en el ámbito de una sociedad restablecida en la que se comparten fines comunes.

En esta línea de argumentación, es forzoso comprender con mayor hondura el concepto de realización personal al que hacemos referencia, puesto que será determinante para juzgar luego, en el terreno, la necesidad y pertinencia de ciertas modalidades de reparación. El concepto de agencia que plantean Amartia Sen y Martha Nussbaum, puede ser útil para este propósito. Por agencia se entiende la posibilidad que tiene un ser humano de elegir y desarrollar el modelo de vida que tiene razones para valorar.

Esta noción ha revolucionado el modo como se mide el desarrollo de los países a escala mundial, al superar criterios económicos y efectuar un análisis más profundo que considera esenciales las libertades de los individuos y el desarrollo de sus capacidades. Las capacidades, también denominadas por Sen libertades sustanciales, son "un conjunto de oportunidades (habitualmente interrelacionadas) para elegir y actuar". 35

En una línea semejante se ha pronunciado la Corte Interamericana al desarrollar el concepto de proyecto de vida como consustancial al derecho a la existencia digna. De acuerdo con el tribunal:

[e]1 "proyecto de vida" se asocia al concepto de realización personal, que a su vez se sustenta en las opciones que el sujeto puede tener para conducir su vida y alcanzar el destino que se propone. En rigor, las opciones son la expresión y garantía de la libertad. Difícilmente se podría decir que una

35 Martha Nussbaum, Crear capacidades. Propuesta para el desarrollo humano, 40 (Paidós, Barcelona, 2012); Amartya Sen, Desarrollo y libertad (Ed. Planeta, Colombia, 2000). 
persona es verdaderamente libre si carece de opciones para encaminar su existencia y llevarla a su natural culminación. ${ }^{36}$

Ahora bien, desde la perspectiva del bien común, ni la agencia ni el proyecto de vida pueden entenderse al modo del liberalismo individualista, exacerbando la libertad personal con desapego a todo lo social. Por el contrario, como se afirmó, el bien común supone la realización personal de todos los miembros de la comunidad y trasciende esas realizaciones individuales para la consecución de fines compartidos y mayores que los unen.

Esta idea coincide con la noción de personal flourishment desarrollada por John Finnis, y referenciada supra §3, a partir de la cual se propende por la realización de principios prácticos básicos que identifican las formas básicas de la plenitud humana como bienes que han de ser perseguidos y realizados. ${ }^{37}$ En efecto, Nussbaum hace referencia a ciertas capacidades centrales que configuran el umbral de aquello que se debe garantizar para que una vida humana sea digna. ${ }^{38}$

36 Corte IDH. Caso Loayza Tamayo contra Perú. Reparaciones y costas. Sentencia del 27 de noviembre de 1998. Serie C N. ${ }^{\circ} 42$, párr. 148.

37 Joaquín Rodríguez-Toubes Muñiz, El iusnaturalismo de Finnis, Anuario de Filosofía del Derecho, X, 375-406, 376 (1993).

38 Martha Nussbaum, Crear capacidades. Propuesta para el desarrollo humano, 53 y ss. (Paidós, Barcelona, 2012). "Podemos deducir que un orden político aceptable está obligado a procurar a todos los ciudadanos y ciudadanas un nivel umbral de las siguientes capacidades centrales: 1) Vida: poder vivir hasta el término de una vida humana de una duración normal; no morir de forma prematura o antes de que la propia vida se vea tan reducida que no merezca la pena vivirla. 2) Salud física [...]. 3) Integridad física: poder desplazarse de un lugar a otro; estar protegidos de ataques violentos, incluidas las agresiones sexuales y la violencia doméstica; disponer de oportunidades para la satisfacción sexual y para la elección en cuestiones reproductivas. 4) Sentidos, imaginación y pensamiento: poder utilizar los sentidos, la imaginación, el pensamiento y el razonamiento y hacerlo de un modo "verdaderamente humano", un modo formado y cultivado por una educación adecuada que incluya (aunque ni mucho menos esté limitada a) la alfabetización y la formulación matemática y científica básica. Poder usar la imaginación y el pensamiento para la experimentación y la producción de obras y actos religiosos, literarios, musicales o de índole parecida, según la propia elección. Poder usar la propia mente en condiciones protegidas por la libertad de expresión política y artística y por la libertad de práctica religiosa. Poder disfrutar de experiencias placenteras y evitar el dolor no beneficioso. 5) Emociones: [...]; en general poder amar, apenarse, sentir añoranza, gratitud e indignación justificada [...]. 6) Razón práctica: poder formarse una concepción del bien y poder reflexionar críticamente acerca de la planificación de la propia vida. (Esta capacidad entraña la protección de la libertad de conciencia y de observancia religiosa). 7) Afiliación: a) Poder vivir con y para los demás, reconocer y mostrar interés por otros seres humanos, participar en formas diversas de interacción social [...]. b) Disponer de las bases necesarias para que no sintamos humillación y sí respeto por nosotros mismos; que se nos trate como seres dignos de valía igual a la de los demás. Esto supone introducir disposiciones que combatan la discriminación [...]. 8) Otras 
Más allá de las similitudes o diferencias específicas que puedan existir entre estos conceptos - bienes humanos básicos y capacidades centrales-, lo que se quiere resaltar es la necesidad de que al establecer las reparaciones por violaciones a los derechos humanos que serán otorgadas en una sociedad en transición de conflicto armado a paz, se parta de una visión trascendental que supere el análisis del daño particular y concreto, que considere los factores individuales y colectivos que permitieron que las violaciones a los derechos humanos se repitieran históricamente, que se enfilen al logro de los fines comunes esenciales de la transición y, bajo esos presupuestos, que tienda a la consecución del bien común.

Consecuentes con lo expuesto, puede afirmarse que en una sociedad en transición resulta esencial que las políticas relacionadas con el reconocimiento y otorgamiento de reparaciones por las graves violaciones a los derechos humanos que tuvieron lugar en el conflicto armado, promuevan no solo ni principalmente la restitución del daño sufrido por cada víctima, sino sobre todo, la superación de fallas estructurales y contextos de desigualdad crónica que están en la base misma del conflicto que se busca superar. ${ }^{39}$ Pero, además, una visión de las reparaciones asentada

especies: poder vivir una relación próxima y respetuosa con los animales, las plantas y el mundo natural. 9) Juego: poder reír, jugar y disfrutar de actividades recreativas. 10) Control sobre el propio entorno: a) Político: poder participar de forma efectiva en las decisiones políticas que gobiernan nuestra vida; [...] b) Material: [...] ostentar derechos de propiedad en igualdad de condiciones con las demás personas; tener derecho a buscar trabajo en plano de igualdad con los demás; estar protegidos legalmente frente a registros y detenciones que no cuenten con la debida autorización judicial. En el entorno laboral, ser capaces de trabajar como seres humanos, ejerciendo la razón práctica y manteniendo relaciones valiosas y positivas de reconocimiento mutuo con otros trabajadores y trabajadoras".

39 Catalina Díaz et al., Reparar en Colombia, 33, 44 y ss. (1 ${ }^{\text {a }}$. Ed., ICTJ-Dejusticia, Bogotá, 2009). En el Caso González y otras, Campo Algodonero Corte IDH, Caso González y otras ("Campo algodonero") contra México. Excepción preliminar, fondo, reparaciones y costas. Sentencia del 16 de noviembre de 2009. Serie C N. ${ }^{\circ} 205$. La Corte Interamericana incluyó esta perspectiva en su jurisprudencia relacionada con la obligación de reparar violaciones a los derechos humanos, cuyo enfoque había sido clásicamente restitutivo. Sobre este punto el Tribunal señaló que "la Corte recuerda que el concepto de "reparación integral" (restitutio in integrum) implica el restablecimiento de la situación anterior y la eliminación de los efectos que la violación produjo, así como una indemnización como compensación por los daños causados. Sin embargo, teniendo en cuenta la situación de discriminación estructural en la que se enmarcan los hechos ocurridos en el presente caso y que fue reconocida por el Estado (supra párrs. 129 y 152), las reparaciones deben tener una vocación transformadora de dicha situación, de tal forma que las mismas tengan un efecto no solo restitutivo sino también correctivo. 
sobre el bien común exige que estas sean ponderadas de tal modo que las condiciones que se pretende configurar no generen un desmedro en las condiciones básicas que requieren el resto de miembros de la comunidad para que puedan alcanzar también ellos su propia realización personal.

Así visto, el componente de reparaciones de un sistema integral de justicia transicional se justifica sobre la necesidad de alcanzar el bien común al que se aspira con la transición, cuyos fines le son inherentes -fundamentalmente, la reconciliación social y la paz-, pero también encuentran su límite en el mismo bien común, pues este exige una adecuada articulación de las muy distintas condiciones básicas que requieren, no solo las víctimas directas del conflicto, sino todos los miembros de la sociedad colombiana para realizarse en su máximo potencial

\section{A MODO DE COLOFÓN: CONSECUENCIAS PRÁCTICAS DE UNA PERSPECTIVA TELEOLÓGICA DE LAS REPARACIONES}

A la pregunta polémica que, en parte, nos incitó a este estudio, hemos respondido de manera afirmativa pero condicionada. Sobre si es justo que el Estado, es decir, todos los colombianos, deban garantizar las reparaciones a las víctimas de las graves violaciones a los derechos humanos suscitadas a raíz del conflicto armado, se ha recurrido a una teoría de la justicia que justificaría dicha obligación en consideración, no principalmente de los

\footnotetext{
En este sentido, no es admisible una restitución a la misma situación estructural de violencia y discriminación [...]. Conforme a ello, la Corte valorará las medidas de reparación solicitadas por la Comisión y los representantes de forma que estas: i) se refieran directamente a las violaciones declaradas por el Tribunal; ii) reparen proporcionalmente los daños materiales e inmateriales; iii) no signifiquen enriquecimiento ni empobrecimiento; iv) restablezcan en la mayor medida de lo posible a las víctimas en la situación anterior a la violación en aquello en que no se interfiera con el deber de no discriminar; v) se orienten a identificar y eliminar los factores causales de discriminación; vi) se adopten desde una perspectiva de género, tomando en cuenta los impactos diferenciados que la violencia causa en hombres y en mujeres y vii) consideren todos los actos jurídicos y acciones alegadas por el Estado en el expediente tendientes a reparar el daño ocasionado". (Negrilla fuera del original) Corte IDH, Caso González y otras ("Campo algodonero") contra México. Excepción preliminar, fondo, reparaciones y costas. Sentencia del 16 de noviembre de 2009. Serie C N. ${ }^{\circ} 205$. párrs. 450 y 451.
} 
agravios personales que no siempre pueden endilgarse al Estado (y esta es una cuestión irrelevante en el marco de transición puesto que clasificar a las víctimas para reconocer sus derechos según los autores de las afrentas resulta ser una injusticia mayor), sino de la importancia de alcanzar un bien común para la nueva sociedad. Así, con esta noción, se ha planteado la necesidad de que las reparaciones se centren, especialmente, en la consolidación de las condiciones que habiliten a las víctimas de las más graves violaciones a retomar y recomponer sus proyectos de vida y, a la vez, con visión teleológica, se conformen a esos fines últimos a los que aspira la transición, esto es, la reconciliación social y la paz estable y duradera.

En todo caso, las reparaciones están condicionadas por la misma razón que las justifica: el bien común. Adherir a este concepto exige integrar los principios y valores que se privilegian en el posconflicto, como condiciones para consolidar la paz. De este modo, un programa de reparaciones que vaya en desmedro de otros miembros de la misma sociedad en relación con condiciones legítimas y esenciales para su realización personal, resultaría injustificable.

Así como se han justificado y condicionado, también se ha hecho un esfuerzo por explicar de qué modo se puede potenciar el papel de las reparaciones en función de los fines últimos que sustentan un modelo de justicia transicional. Del análisis teórico que se ha propuesto, se pueden colegir tres consecuencias prácticas, a modo de efectos jurídico-políticos que se desprenderán de la concepción teleológica y pluridimensional que se expuso.

En primer lugar, el debate público sobre los programas de reparaciones tendrá que asumir nuevos conceptos que giran en torno a los principios y valores que se han privilegiado en el modelo transicional, que se expresan en términos de fines comunes y que no solo tienen implicaciones económicas, sino también culturales. Esto es claro si se asumen seriamente valores como 
la solidaridad, la compasión, el reconocimiento de la dignidad humana y la confianza, por mencionar algunos esenciales. ${ }^{40}$

Por otro lado, el concepto de bien común además de ser útil teóricamente para justificar y condicionar las reparaciones es también exigente en términos prácticos. Por eso resulta urgente que el Estado presente evidencias públicas de los avances en la implementación de los programas de reparaciones pluridimensionales, como respaldo a un compromiso serio con los objetivos trazados con la transición.

Ahora bien, si el compromiso al que se refiere el punto anterior es probado, el alcance del principio de subsidiaridad impondrá a los órganos internacionales de derechos humanos un especial self-restraint para dictaminar reparaciones por fuera del sistema nacional. Se acude a esa autorrestricción 1) para pronunciarse sobre casos relacionados con el conflicto armado y declarar la responsabilidad internacional del Estado respecto a ellos-ya que uno de los elementos que permite señalar que un ilícito internacional ha sido subsanado en el ámbito interno es precisamente la reparación adecuada de las víctimas-; o 2) por lo menos, para abstenerse de ordenar reparaciones externas al sistema nacional. En este sentido, la fuerza del bien común al que se aspira para los colombianos tendrá que servir para contener reparaciones exorbitantes que quieran obtenerse por fuera del modelo que se ha diseñado para hacer frente a un pasado con el que tenemos que hacer las paces para dejar de recordarlo.

40 Así, por ejemplo, en la base del propósito que indica que "las medidas de atención, asistencia y reparación tendrán la finalidad de contribuir a que las víctimas sobrelleven su sufrimiento" subyacen la compasión y la solidaridad como valores que se enaltecen. La invitación a involucrar a la sociedad civil y la empresa privada a la consecución de la reconciliación nacional y la materialización de los derechos de las víctimas refuerza ese principio de solidaridad, que se expresa de muchas maneras y de forma transversal en el modelo colombiano. El eje de reconocimiento de las víctimas tanto en su sufrimiento como en los derechos que de él se derivan, es una concreción del principio de dignidad humana. 


\section{BIBLIOGRAFÍA}

Libros

Alfonso, Santiago, En las fronteras entre el derecho constitucional y la filosofía del derecho (Ed., Marcial Pons, Buenos Aires, 2010).

Bersgsmo, Morten et al. Justicia distributiva en sociedades en transición (Torkel Opsahl Academic EPublisher \& Peace Research Institute Oslo, Oslo, 2012).

Díaz, Catalina et al., Reparar en Colombia (1ª. Ed., ICTJ-Dejusticia, Bogotá, 2009).

Finnis, John, Ley natural y derechos naturales (Oxford, Clarendon Press, 1992).

Londoño María Carmelina, Las garantías de no repetición en la jurisprudencia interamericana. Derecho Internacional y cambios estructurales del Estado (Ed., Tirant lo Blanch, 2014).

Nussbaum, Martha, Crear capacidades. Propuesta para el desarrollo humano (Paidós, Barcelona, 2012.

Sandel, Michael J. Justicia: ¿Hacemos lo que debemos? (Ed. Random House Mondadori, Barcelona, 2011).

\section{Colaboración en obras colectivas}

Rodríguez-Toubes Muñiz, Joaquín, El iusnaturalismo de Finnis, Anuario de Filosofía del Derecho, X, (1993).

Uprimny, Rodrigo, Reparaciones transformadoras: un mecanismo para aliviar tensiones entre justicia correctiva y justicia distributiva, en Democracia, Justicia y Sociedad Diez años de investigación en Dejusticia (Mauricio, García \& María Ceballos Coord., Dejusticia, Bogotá, 2016).

\section{Jurisprudencia colombiana}

Acto Legislativo 01 de 2012 "marco jurídico para la paz", por medio del cual se establecen instrumentos jurídicos de justicia transicional en el marco del artículo 22 de la Constitución Política y se dictan otras disposiciones, 48508 Diario Oficial, 31 de julio de 2012.

Acto Legislativo 01 de 2017, por medio del cual se crea un título de disposiciones transitorias de la constitución para la terminación del conflicto armado y la construcción de una paz estable y duradera y se dictan otras disposiciones, 50196 Diario Oficial, 4 de abril de 2017.

Corte Constitucional de Colombia, Sala Plena, Sentencia C-333 de 1996, Expediente D-1111, Actora: Emilse Margarita Palencia Cruz. Magistrado Ponente: Alejandro Martínez Caballero.

Corte Constitucional de Colombia, Sala Plena, Sentencia C-916 de 2002, Expediente: D-4020, Actor: Camilo Andrés Baracaldo Cárdenas. Magistrado Ponente: Manuel José Cepeda Espinosa. 
Corte Constitucional de Colombia, Sala Plena, Sentencia C-370 de 2006, Expediente

D-6032, Actor: Gustavo Gallón Giraldo y otros, Magistrados Ponentes: Manuel José

Cepeda Espinosa, Jaime Córdoba Triviño, Rodrigo Escobar Gil, Marco Gerardo

Monroy Cabra, Álvaro Tafur Galvis, Clara Inés Vargas Hernández.

Corte Constitucional de Colombia, Sala Plena, Sentencia C-052 de 2012, Expediente

D-8593, Actor: Jesús Antonio Espitia Marín, Magistrado Ponente: Nilson Pinilla Pinilla.

Corte Constitucional de Colombia, Sala Plena, Sentencia SU-254 de 2013, Expediente T-2.406.014 y acumulados, Magistrado Ponente: Luis Ernesto Vargas Silva.

Corte Constitucional de Colombia, Sala Plena, Sentencia C-912 de 2013, Expediente D-9683, Actores: Luis Jorge Garay Salamanca y otros. Magistrada Ponente María Victoria Calle Correa.

Corte Constitucional de Colombia, Sala Plena, Sentencia C-286 de 2014, Expediente D-9930, Actor: Gustavo Gallón Giraldo y otros. Magistrado Ponente: Luis Ernesto Vargas Silva

Corte Constitucional de Colombia, Sala Plena, Sentencia C-006 de 2017, Expediente D-11481, Magistrado Sustanciador: Gloria Stella Ortiz Delgado.

Ley 975 de 2005 “de Justicia y Paz", por la cual se dictan disposiciones para la reincorporación de miembros de grupos armados organizados al margen de la ley, que contribuyan de manera efectiva a la consecución de la paz nacional y se dictan otras disposiciones para acuerdos humanitarios, 45980 Diario Oficial, 25 de julio de 2005.

Ley 1448 de 2011, por la cual se dictan medidas de atención, asistencia y reparación integral a las víctimas del conflicto armado interno y se dictan otras disposiciones, 48096 Diario Oficial, 10 de junio de 2011.

\section{Jurisprudencia de Tribunales internacionales}

Corte IDH, Caso Acosta y otros contra Nicaragua. Excepciones preliminares, fondo, reparaciones y costas. Sentencia de 25 de marzo de 2017. Serie C N. ${ }^{\circ} 334$.

Corte IDH, Caso Masacres de Ituango contra Colombia. Sentencia de 1 de julio de 2006. Serie C N. ${ }^{\circ} 148$.

Corte IDH, Caso González y otras (“Campo algodonero") contra México. Excepción preliminar, fondo, reparaciones y costas. Sentencia de 16 de noviembre de 2009. Serie C N. ${ }^{\circ} 205$.

Corte IDH, Caso Loayza Tamayo contra Perú. Reparaciones y costas. Sentencia de 27 de noviembre de 1998 . Serie C N. 42.

Corte IDH, Caso Masacre de Pueblo Bello. Sentencia de 31 de enero de 2006. Serie C. N. ${ }^{\circ} 140$.

Corte IDH, La Colegiación Obligatoria de Periodistas (Arts. 13 y 29 Convención Americana sobre Derechos Humanos). Opinión Consultiva OC-5/85 del 13 de noviembre de 1985. Serie A N. ${ }^{\circ} 5$. 


\section{Otros documentos}

Acuerdo final para la terminación del conflicto y la construcción de una paz estable y duradera. http://www.altocomisionadoparalapaz.gov.co/procesos-y-conversaciones/Documentos\%20compartidos/24-11-2016NuevoAcuerdoFinal.pdf (Acuerdo de paz). (26 de noviembre de 2016).

Argandona Antonio, El bien común, Documento de Investigación DI-937, IESE Business School, julio de 2011.

Centro Carr para la Política de Derechos Humanos y la Iniciativa Humanitaria de Harvard. Evaluación de medidas de reparación integral: logros y retos. https:// www.yumpu.com/es/document/view/55955747/evaluacion-de-medidas-parareparaciones-integrales-en-colombia-logros-y-retos (octubre de 2015).

Congreso de la República. Gacetas del Congreso. Cámara de Representantes: 943/2015; 1010/2015; 29/11/2015; 09/10/2015; 890/2015; 1043/201; 276/2016; 367/2016.

Congreso de la República. Gacetas del Congreso. Senado de la República: 776/2015; 21/2016; 6/10/2015; 14/2016; 890/2015; 1042/2015; 113/2016; 158/2016; 405/2016; $364 / 2016$.

Organización de Naciones Unidas, Informe del Relator Especial sobre la promoción de la verdad, la justicia, la reparación y las garantías de no repetición. Pablo de Greiff, Asamblea General, A/HRC/21/46, 9 de agosto de 2012.

Organización de Naciones Unidas. Informe del Relator Especial sobre la promoción de la verdad, la justicia, la reparación y las garantías de no repetición. Pablo de Greiff, Asamblea General A/HRC/30/42, 7 de septiembre de 2015.

Organización de Naciones Unidas, Primer informe oficial del Consejo de Seguridad de las Naciones Unidas sobre El Estado de derecho y la justicia de transición en las sociedades que sufren o han sufrido conflicto, Consejo de Seguridad S/2004/616, 3 de agosto de 2004,

Organización de Naciones Unidas, Principios y directrices básicos sobre el derecho de las víctimas de violaciones manifiestas de las normas internacionales de derechos humanos y de violaciones graves del derecho internacional humanitario a interponer recursos y obtener reparaciones, Asamblea General 147/ 2005,16 de diciembre de 2005. 
